\title{
Problems and Measures of Master of Fine Arts Education Within International Comparative Perspective*
}

\author{
Lin Lin, Li Yunpeng \\ Shandong Women's University, Jinan, China
}

\begin{abstract}
Master of Fine Arts (MFA) is a kind of professional master degree, which started in 2005 in China. In order to conclude China's MFA achievements and problems, this paper use comparison method to find out China's main problems which are mainly in attribute three parts-positioning, training models, and quality evaluation system. Based on these three problems, this paper use international experiences to suggest China to use three strategies to improve the quality of China's MFA education, which are to clear MFA objectives, cultivate mode of MFA, and optimize MFA quality evaluation system. In addition, China should make efforts to improve MFA's importance in society, to make clear the difference between MFA and Master of Arts (MA) in Art, and to make MFA a different but outstanding professional master degree. China should make MFA be an international degree to share the same discipline.
\end{abstract}

Keywords: master of fine arts, professional degree, international comparison

\section{Introduction}

In the 2016, China's Ministry of Education announced, "National Council Academic Degree Committee is on the release of the 2014 degree authorization special assessment results and advices." Master of Fine Arts (MFA) has two "unqualified" and 15 "deadline for rectification" (State Council Academic Degrees Committee, 2016). The problems of MFA are focused on the goal of personnel training, the construction of teaching staff, curriculum system, and so on. It is of great theoretical and practical significance to summarize the achievements of MFA education in China from the perspective of international comparison, to explore the problems in China and to find solutions.

\section{Achievements of China's MFA Education}

Since the beginning of MFA in 2005, the number of institutions to implement MFA rapidly increase from the initial 32 to the present 202. By 2015, China has a total enrollment of MFA about 50,000 people, more than 15,000 graduates have received a master's degree (State Council Academic Degrees Committee, 2016). The vigorous development of MFA education has greatly promoted the transformation of the concept of art graduate education, innovated the training mode of high-level art talents, and founded a high-quality artistic talent team.

\footnotetext{
* Acknowledgement: This research is financially supported by Shandong Province Humanities and Social Sciences Fund "Lu Southwest Lu Guchui Music Club Change Research-Art Anthropology Perspective" (Grant No. J16YH05), Preschool Teacher Education Talent Team-Advantage Disciplines Cultivation Plan of Shandong Provincial Higher Education Institutions Lin Lin, M.A., associate professor, School of Music, Shandong Women's University. Li Yunpeng, Ph.D., researcher, School of Education, Shandong Women's University.
} 
After over 10 years' efforts, the training system of China MFA has been basically formed, the scale of training institutions and students is growing, the establishment of a standardized enrollment system, training system, curriculum and teaching system, quality assessment system, and degree award system, which has played an important role in ensuring the benign development of MFA education.

At present, China is actively adjusting the existing graduate structure, to increase the development of professional degrees which are based on the application of practical talents. Since 2010, China has started full-time professional degree education enrollment and training. Private colleges and universities began to recruit MFA. These indicate that the cultivation of MFA's scale will continue to expand. At the same time, how to ensure the quality of MFA training has become an increasingly important and urgent research topic.

\section{China's MFA Education Problems}

Compared with the developed countries, there are still some shortcomings in the aspects of MFA educational concepts, training methods, and running conditions, which lead to the key issues, such as attribute orientation, training mode, and evaluation system have not reached a scientific consensus, affecting the quality of MFA's education.

\section{Unclear Attribute Positioning}

MFA Professional Degree Training Guideline pointed out that MFA is to cultivate a system of professional knowledge and high level of art design skills, applied art professionals with systematic expertise, high level of artistic design, and strong artistic understanding and expression (MFA Education Commission Secretariat, 2015). It can be said that this attributes positioning is very clear. But the problem is that because of the difference between the conditions of running schools in China is very large, and the reality is that different institutions of the same professional training objectives convergence phenomenon is very prominent, and even different professional training model is also very similar. The reason is that institutions did not develop a suitable distinctive and personalized development strategy for their own characteristics of the development orientation. Many MFA educations have not well grasped and shown their professional characteristics in the training process, whereas there is a more academic, less practice improper tendency.

In contrast, some approaches from the developed countries are worth learning. American MFA training institutions have their own clear educational purposes, clear and specific training objectives of sub-disciplines in the field, embody the strengths and characteristics of the colleges and universities, emphasizing the personalized training, student training program due to student specialized field, different from the individuals. At the same time, all training institutions emphasize that the MFA is a practice-oriented professional degree, emphasizing the cultivation of students into professional art practitioners or artists. "The American Association of Art Colleges and the American Federation of Professional Arts and Design found that MFA is practical, creative, and emphasizing application. It requires the necessary artistic accomplishment and theoretical knowledge" (Jiang, 2005, p. 84). The American MFA curriculum design and course content are closely related to the future career needs, cultivating marketable high-level art professionals.

\section{Similar Training Models}

At present, China's society is in a period of rapid transformation, the demand for art talents is continually changing, and the current MFA's training model is lagging. The following are to analyze from the curriculum system and teaching model two aspects. 
Curriculum system is not perfect. It mainly lies in the three aspects.

The total number of courses is small. The American MFA program system is rich. For example, MFA in the American Film requires 60 credits, including: MFA specialized field 36 credits; ex-specialized film courses six credits; art history 12 credits; art research methods three credits; and written thesis three credits. In contrast, MFA in China is less than 32 credits, including less than 24 credits for compulsory courses, no less than eight credits for public courses, no less than 16 credits for professional courses; and elective courses no less than eight credits. Compared with United States (U.S.), the number of professional courses in China's MFA is obviously insufficient, the scope of elective courses is very small, the number of research methods is even less, and even in some schools it is also almost blank.

The number of practical courses. The number of practical courses, about the total number of courses $1 / 3$, while the US colleges and universities require MFA professional practice courses accounted for all required courses $60 \%$ to $65 \%$ (Boukalsky, 2001, p. 178). More than $85 \%$ of the courses offered by the Berlin Academy of Music in Germany are practical courses (University of Oregon, 2016). There are not only the shortage of resources and the shortage of teachers and other objective reasons, but also subjective reasons which cultivate old concepts. Although we generally emphasize the theory and practice in the topic of student thesis, the practical practice plan is designed, the lack of practical curriculum training will inevitably affect the cultivation of students' practical ability.

Lack of interdisciplinary courses. MFA in US cultivates an interdisciplinary approach to cultivating institutions that practice interdisciplinary courses through establishment of interdisciplinary research centers, allowing students to pursue interdisciplinary and even cross-disciplinary. For example, MFA program in the University of Oregon is committed to cultivating students strictly independence in the arts practice ability. The courses require students to the professional sculpture, photography, and other nine areas, which are combined to achieve the depth of disciplines and interdisciplinary thinking. It emphasizes students' involvement in practice and teaching, participating in many seminars and conducting independent research and creation (Liu, 2015, p. 102). Some institutions in U.S. also require MFA graduate to go to the relevant institutes to study the relevant courses of education, sociology, and so on, obtaining corresponding credits. To a certain extent, these requirements expand the study scope of MFA. The curriculum of China's MFA is more emphasized on the field of professional courses. The scope of elective courses is relatively narrow. Ignoring the art disciplines have the cross-nature property results in narrow vision of students, thinking rigid, and lack of innovation capacity.

Teaching models lag behind. American MFA offers many seminars. The seminars are divided into professional seminars and interdisciplinary seminars. The professional seminars are conducted in a group discussion, topic analysis, and panel discussion. Seminars encourage students to participate actively in the discussion. Students report their own research results, while other teachers and students comment and discuss. This approach helps teachers and students in different directions learn from each other and exchange. New Zealand Otago Institute of Technology emphasizes cohort MFA learning, which includes regular workshops, research workshops, discussions, and debates to expand students' opportunities for reflection and feedback, while teachers are responsible for the entire process. On a whole, China's MFA education neglects the cultivation of the students' comprehensive quality, especially the humanistic accomplishment. The works they produce lack innovation consciousness and individuality characteristics. 


\section{Imperfect MFA Education Quality Evaluation System}

China's MFA quality evaluation system is more like one-sided, academic standards relatively low. In the case of music professional, many thesis or graduation designs only describe some of the musicians' life, composition, and writing background. MFA graduates rarely personalize theoretical analysis of the process of re-creation, rarely in-depth interpretation of their creative material understanding. The reason is that there is no balance between mastering the "high level of creative skills" and "rich system expertise" in the process of master's education. Most MFA graduates have no ability to analyze, study, and summarize professional problems.

China's MFA quality evaluation is more focus on the results than the process of evaluation and after graduation career development evaluation. The American MFA education has formed a complete evaluation system composed of process evaluation, graduation evaluation and post-graduate development evaluation, which play an important role in protecting the quality of MFA. Particularly post-graduate development evaluation is of great significance to the institution's social reputation, enrollment, and social donation, so the institutions attach great importance to it.

The evaluation indicators are mainly from external professional groups. The College Art Association (CAA) and the American Association of Professional Arts and Design (AICAD) have conducted detailed provisions on the quality of MFA, emphasizing the applicability, but also requiring a higher artistic quality and professional theoretical knowledge. The degree of awarding is mainly to see the artistic creation skills and expressive power embodied in the process of students' creative practice.

\section{Strategies to Improve the Quality of China's MFA Education}

\section{Clearing MFA Education Objectives}

In contrast to academic master, MFA more emphasizes students' ability to practical innovation, solve practical problems in the work, and pay more attention to the improvement of creative skills, and the cultivation of artistic theory and intrinsic quality. Therefore, students should not only have solid basic theory knowledge, but also strong professional practice ability. Japan sets up MFA according to each institute's research characteristics and combined with social needs to set different research areas. In contrast, China's professional settings are subject-oriented, but Japan is a social-orientation. Ideally, we should combine the two. It is necessary to consider the academic capacity of institutions. According to professional requirements to cultivate the application of art talent, based on institution's research characteristics and resource advantages, combined with social needs. Making sure MFA really is a professional-oriented professional degree.

\section{Cultivating Mode of MFA Education}

Cultivating the training mode of MFA mainly includes three aspects: optimizing the curriculum system, improving the teaching mode, and innovating the mode of running the school.

To optimize the curriculum system, multi-disciplinary cross-infiltration of the curriculum system should be constructed. Art is a very comprehensive application of science, involving sociology, literature, aesthetics, economics, and other disciplines. China should set up a comprehensive interdisciplinary curriculum for the arts students to provide relevant interdisciplinary courses, to expand MFA's professional courses in depth and breadth, both to strengthen the basic theory of learning, but also to cultivate and inspire students to use multidisciplinary knowledge to solve practical problems. To expand the practice courses. 
For MFA students, exposure to a lot of artistic practice and the latest art dynamics, can effectively stimulate their artistic creativity. MFA training in Nanjing Normal University increases the proportion of creative practice courses, such courses accounted for the proportion of total credits more than $60 \%$, while the proportion of theoretical courses credits to $36 \%$. It is designed by changing the curriculum to enhance the creative ability of the MFA (Sun, Xue, \& Liu, 2014, p. 22).

\section{Optimizing MFA Education Quality Evaluation System}

Compared with the MFA, MFA is a considerable level of similar degree, must have a certain quality standards. The evaluation of MFA should not only adhere to the practical characteristics of professional degrees, but also adhere to the high theoretical level. In the evaluation system, China should improve the evaluation system composed of process evaluation, graduation evaluation, and post-graduate development evaluation as soon as possible. China should form strict and regular evaluation guidance, and strength the supervision.

The recognition of MFA in Chinese society has yet to be improved. This is because of people's traditional concept, as well as the low quality of MFA. There is still a long way to go for MFA in China.

\section{Conclusion}

According to international experiences, professional degrees including MFA are an important part of higher education degrees, and are playing a more and more important role in social economic development. But in China, owing to traditional concept, professional degrees are regarded a second-level to the academic degrees. Also, owing to strong influence of academic degrees, professional degrees always follow academic degree's modes, which make a great confusion to the society and researchers. China as a less developed can make use of other national good experiences to make a faster development. Surely, China should consider its particular national environment, but something is common in higher education development. In this sense, China should make MFA an international degree to share the same discipline.

\section{References}

Boukalsky, P. J. (2001). Film and television MFA course outline I. World Film, 236(5), 172-180. (in Chinese)

Department of Art, University of Oregon. (2016). Retrived December 20, 2016, from http://art-uo.uoregon.edu/index. $\mathrm{cfm}$ ?mode=academics\&page $=$ grad.

Jiang, H. (2005). Thought on the work of the pilot MFA work. New Art, 54(4), 84-85. (in Chinese)

Liu, X. (2015). MFA (music) practical ability cultivation research (p. 102) (Master thesis, Fujian Normal University). (in Chinese)

MFA Education Commission Secretariat. (2015). Notice on the guidance program for the development MFA. Retrived December 20, 2016, from http://www.mfa.edu.cn/news_423.html.

State Council Academic Degrees Committee. (2016). Notice of the academic degrees committee of the state council on the results and opinions on the special evaluation of degree authorization in 2014. Retrived November 11, 2016, from http://www.cdgdc.edu.cn/xwyyjsjyxx/zxkb/hyxx/yyxz/282928.shtml

Sun, Y. 1., Xue, J. W., \& Liu, S. (2014). MFA education and creativity training-Nanjing Normal University MFA education reform. Degree and Education, 254(1), 20-23. (in Chinese) 